\title{
Deuterium Kinetic Isotope Effects in Microsolvated Gas-Phase E2 Reactions: Methanol and Ethanol as Solvents
}

\author{
Nicole Eyet, Stephanie M. Villano, and Veronica M. Bierbaum \\ Department of Chemistry and Biochemistry, University of Colorado, Boulder, Colorado, USA
}

\begin{abstract}
The gas-phase reactions of $\mathrm{F}^{-}\left(\mathrm{CH}_{3} \mathrm{OH}\right)$ and $\mathrm{F}^{-}\left(\mathrm{C}_{2} \mathrm{H}_{5} \mathrm{OH}\right)$ with $t$-butyl bromide have been investigated to explore the effect of the solvent on the $\mathrm{E} 2$ transition state. Kinetic isotope effects (KIEs) were measured using a flowing afterglow-selected ion flow tube (FA-SIFT) mass spectrometer upon deuteration of both the alkyl halide and the alcohol. Kinetic isotope effects are significantly more pronounced than those previously observed for similar reactions of $\mathrm{F}^{-}\left(\mathrm{H}_{2} \mathrm{O}\right)$ with $t$-butyl halides. KIEs for the reaction of $\mathrm{F}^{-}\left(\mathrm{CH}_{3} \mathrm{OH}\right)$ with $t$-butyl bromide are 2.10 upon deuteration of the neutral reagent and 0.74 upon deuteration of the solvent. KIEs for the reaction of $\mathrm{F}^{-}\left(\mathrm{C}_{2} \mathrm{H}_{5} \mathrm{OH}\right)$ with $t$-butyl bromide are 3.84 upon deuteration of the neutral reagent and 0.66 upon deuteration of the solvent. The magnitude of these effects is discussed in terms of transition-state looseness. Additionally, deuteration of the neutral regent and deuteration of the solvent do not produce completely separable isotope effects, which is likely due to a crowded transition state. These results are compared to our previous work on $\mathrm{S}_{\mathrm{N}} 2$ and E2 solvated systems. (J Am Soc Mass Spectrom 2008, 19, 1296-1302) @ 2008 American Society for Mass Spectrometry
\end{abstract}

$\mathrm{F}$ undamental organic reactions, such as substitutions and eliminations, have for decades been studied in solution $[1,2]$, and more recently have been extensively studied in the gas phase as well [3-9]. While these prototypical condensed-phase and gasphase reactions are relatively well understood, significant differences in the reactivity of species in these phases have been observed [10-15]. For example, the acidities of aliphatic alcohols in the gas phase, observed by Brauman and Blair [16] to be $t-\mathrm{C}_{4} \mathrm{H}_{9} \mathrm{OH}>$ iso$\mathrm{C}_{3} \mathrm{H}_{7} \mathrm{OH}>\mathrm{C}_{2} \mathrm{H}_{5} \mathrm{OH}>\mathrm{CH}_{3} \mathrm{OH}>\mathrm{H}_{2} \mathrm{O}$, have the reverse order of that measured in solution. Additionally, the rate of a reaction usually varies significantly between the solution phase and the gas phase. For example, the reaction of hydroxide with methyl bromide is 16 orders of magnitude faster in the gas-phase compared with the reaction in aqueous medium [17]. This is due to the need for solvent reorganization as the reaction proceeds in solution, as well as the greater thermodynamic stability of the solvated ion. It is obvious that a single solvent molecule does not mimic the solution phase; however, a study of microsolvated ions will begin to shed light on the transition between these phases.

Kinetic isotope effects (KIEs) are often used to study reaction mechanisms because they are a sensitive probe for transition-state structure. Deuterium KIEs are the

Address reprint requests to Dr. V. M. Bierbaum, Department of Chemistry and Biochemistry, University of Colorado, 215 UCB, Boulder, CO, 803090215, USA. E-mail: Veronica.Bierbaum@colorado.edu ratio of the perprotio to the perdeutero rate constants $\left(\mathrm{KIE} \equiv \mathrm{k}_{\mathrm{H}} / \mathrm{k}_{\mathrm{D}}\right.$.) It is well known from statistical rate theory that rate constants, and hence KIEs, have electronic, translational, vibrational, and rotational contributions. Kinetic isotope effects, however, are primarily due to changes in vibrational modes as a reaction proceeds from the reactants to the transition-state structure. A normal KIE $(>1)$ is a result of the loosening of bonds in the transition state, which causes a decrease in the difference in zero point energy as the reaction proceeds from separated reactants to the transition state. An inverse KIE $(<1)$ results from the tightening of bonds in a transition state, causing an increase in the difference in zero point energy as the reaction proceeds.

Both theoretical and experimental work have been carried out on systems containing microsolvated ions $[4,17-30]$. The fluoride ion is a perfect candidate for microsolvation because it exhibits remarkably different reactivity in the gas phase compared with solution; fluoride is the most reactive halide ion in the gas phase, but the least reactive in solution. Several studies of microsolvated fluoride ions have been carried out. The bimolecular substitution $\left(\mathrm{S}_{\mathrm{N}} 2\right)$ reactions of $\mathrm{F}^{-}\left(\mathrm{H}_{2} \mathrm{O}\right)_{1}$ [28], $\mathrm{F}^{-}\left(\mathrm{H}_{2} \mathrm{O}\right)_{0-5}$ [20], $\mathrm{F}^{-}\left(\mathrm{CH}_{3} \mathrm{OH}\right), \mathrm{F}^{-}\left(\left(\mathrm{CH}_{3}\right)_{2} \mathrm{CHOH}\right)$ and $\mathrm{F}^{-}$(HF) [19] with various methyl halides have been experimentally studied. Inverse isotope effects have been observed for both deuteration of the methyl halide and deuteration of the solvent molecule. Additionally, theoretical studies of the $\mathrm{S}_{\mathrm{N}} 2$ reaction of $\mathrm{F}^{-}\left(\mathrm{H}_{2} \mathrm{O}\right)$ with $\mathrm{CH}_{3} \mathrm{Cl}$ [29] and of $\mathrm{F}^{-}\left(\mathrm{H}_{2} \mathrm{O}\right), \mathrm{F}^{-}\left(\mathrm{CH}_{3} \mathrm{OH}\right)$, and $\mathrm{F}^{-}(\mathrm{HF})$ with a series of methyl halides [30] have been carried 
out. Good agreement between experiment and theoretical work for these $\mathrm{S}_{\mathrm{N}} 2$ systems has been observed. There has been a limited amount of work on elimination reactions. Theoretical studies of the bimolecular elimination (E2) reactions of $\mathrm{F}^{-}(\mathrm{HF})$ with $\mathrm{C}_{2} \mathrm{H}_{5} \mathrm{~F}$ [18] and $\mathrm{FO}^{-}\left(\mathrm{H}_{2} \mathrm{O}\right)$ with $\mathrm{C}_{2} \mathrm{H}_{5} \mathrm{Cl}$ [21] have been reported due to the presence of competitive reaction pathways. However, these studies would be difficult to confirm experimentally. We have recently reported [27] the E2 reactions of $\mathrm{F}^{-}\left(\mathrm{H}_{2} \mathrm{O}\right)$ with $t$-butyl halides. In the present study, the deuterium KIEs for the $\mathrm{E} 2$ reactions of $\mathrm{F}^{-}\left(\mathrm{CH}_{3} \mathrm{OH}\right)$ and $\mathrm{F}^{-}\left(\mathrm{C}_{2} \mathrm{H}_{5} \mathrm{OH}\right)$ with $t$-butyl bromide are examined, to explore the effect of the solvent on the nature of the transition state.

\section{Experimental}

These reactions were carried out in a flowing afterglowselected ion flow tube (FA-SIFT) mass spectrometer [31, 32]. Fluoride was produced by electron impact on $\mathrm{NF}_{3}$ in a flow of helium in the source flow tube. Solvated fluoride ions were formed by association with ethanol or methanol, which is added downstream. The desired reactant ions were mass selected using a quadrupole mass filter and injected into the reaction flow tube, where they were thermally equilibrated to room temperature through collisions with He buffer gas ( 0.5 torr, $\left.10^{4} \mathrm{~cm} \mathrm{~s}^{-1}\right)$. A known flow of $t$-butyl bromide, measured by a calibrated volume technique, was added to the reaction flow tube through a manifold of inlets. The depletion of the reactant ion and formation of the product ions were monitored using a quadrupole mass filter coupled to an electron multiplier. Reaction rate constants are determined by changing the position of the neutral reagent addition, thereby varying the reaction distance and time. The reactions were carried out at $301 \pm 3$ K. Parallel reactions of deuterated reactants were studied under identical conditions.

Reported rate constants are the average of at least three individual measurements, and the stated error bars reflect the standard deviation of these measurements. Errors reported for the kinetic isotope effects are the propagation of the standard deviation. Absolute uncertainties in these rate measurements are $\pm 20 \%$; however some systematic errors cancel in the rate constant ratio, so that the error bars for KIEs are significantly smaller. Neutral reagents were obtained from commercial sources and used without further purification. $\left[\left(\mathrm{CH}_{3}\right)_{3} \mathrm{CBr}, 96 \% ;\left(\mathrm{CD}_{3}\right)_{3} \mathrm{CBr}, 98 \% \mathrm{D} ; \mathrm{NF}_{3}\right.$, 99.7\%; $\mathrm{CH}_{3} \mathrm{OH}, 99 \% ; \mathrm{CH}_{3} \mathrm{OD}, 99 \% \mathrm{D} ; \mathrm{CD}_{3} \mathrm{OD}, 99.8 \% \mathrm{D}$; $\mathrm{C}_{2} \mathrm{H}_{5} \mathrm{OH}, 98 \% ; \mathrm{C}_{2} \mathrm{H}_{5} \mathrm{OD}, 99.5 \%$ D; $\mathrm{C}_{2} \mathrm{D}_{5} \mathrm{OD}, 99.5 \%$ D.] Helium buffer gas (99.995\%) was purified by passage through a molecular sieve trap immersed in liquid nitrogen.

Efforts were made to minimize mass discrimination. Estimates of the remaining mass discrimination were carried out through a series of calibration reactions, which span the mass range of our instrument. These reactions were chosen such that a single reactant ion, when allowed to react with a carefully selected neutral reagent, formed a single ionic product. Correction of the reported product ion branching ratios for the bare ion present as a result of collision-induced dissociation of the reactant cluster was necessary since its reaction with $t$-butyl bromide also formed some of the same product ions. This complication was accounted for by monitoring both reactants as a function of time, and subtracting the bare ion contribution from the overall result.

Electronic structure calculations were carried out using the Gaussian 03 [33] program package. Optimized geometries and frequencies of the reactants and the transition states were calculated using density functional theory (B3LYP/6-311 ++ G(d,p) [34, 35]. Cartesian coordinates of all optimized geometries, as well as energies of the transition-state structures, are provided in the Supporting Information (which can be found in the electronic version of this article). Transition states were identified as having exactly one imaginary frequency and by confirmation of movement along the reaction coordinate by animation of this frequency. Results of electronic structure calculations are used in this work for qualitative arguments only; a more thorough computational study is beyond the scope of this paper.

\section{Results and Discussion}

Table 1 summarizes the E2 rate constants, reaction efficiencies, kinetic isotope effects, and clustered product branching ratios for the reactions of solvated fluoride with $t$-butyl bromide, as well as deuterated analogs of the ionic and neutral reagents. The reaction efficiency is defined as the ratio of the experimentally determined rate constant to the collision rate constant; the latter values were calculated using parameterized trajectory collision rate theory [36]. The electric dipole polarizability for $t$-butyl bromide was calculated using the Miller-Savchik method [37], and was found to be $10.8 \times 10^{-24} \mathrm{~cm}^{3}$. The dipole moment for $t$-butyl bromide was calculated using the Gaussian 03 [33] program package as 2.596 D. This calculation also confirmed the electric dipole polarizability. "Neutral $\mathrm{k}_{\mathrm{H}} / \mathrm{k}_{\mathrm{D}}$ " refers to the isotope effect resulting from deuteration of $t$-butyl bromide; " $\mathrm{k}_{\mathrm{ROH}} /$ $\mathrm{k}_{\mathrm{ROD}}$ " refers to the isotope effect resulting from solvating fluoride with an alcohol deuterated only at the $\mathrm{OH}$ functional group; "solvent $\mathrm{k}_{\mathrm{H}} / \mathrm{k}_{\mathrm{D}}$ " refers to the isotope effect observed for fluoride solvated with the perdeutero alcohol. Solvated ions, $\mathrm{Br}^{-}(\mathrm{HF})$ and $\mathrm{Br}^{-}(\mathrm{ROH})$, as well as unsolvated $\mathrm{Br}^{-}$are observed as products of all reactions. Branching fractions given in Table 1 represent the total amount of clustered product observed. For the reactions of $\mathrm{F}^{-}\left(\mathrm{CH}_{3} \mathrm{OH}\right)$ with $t$-butyl bromide only trace amounts of $\mathrm{Br}^{-}\left(\mathrm{CH}_{3} \mathrm{OH}\right)$ are observed. For the reactions of $\mathrm{F}^{-}\left(\mathrm{C}_{2} \mathrm{H}_{5} \mathrm{OH}\right), \sim 20 \%$ of the total clustered products are $\mathrm{Br}^{-}\left(\mathrm{C}_{2} \mathrm{H}_{5} \mathrm{OH}\right)$ ions.

Since these reactions are sufficiently below their collision-controlled limits, the isotope effects measured 
Table 1. E2 reaction rate constants in units of $10^{-10} \mathrm{~cm}^{3} \mathrm{~s}^{-1}$, reaction efficiencies, isotope effects, and branching ratios (BR)

\begin{tabular}{|c|c|c|c|c|c|c|}
\hline Reaction & $\mathrm{k}_{\mathrm{E} 2}$ & $\begin{array}{l}\text { Reaction } \\
\text { efficiency }\end{array}$ & $\begin{array}{c}\text { Neutral } \\
\mathrm{k}_{\mathrm{H}} / \mathrm{k}_{\mathrm{D}}\end{array}$ & $\mathrm{k}_{\mathrm{ROH}} / \mathrm{k}_{\mathrm{ROD}}$ & $\begin{array}{c}\text { Solvent } \\
k_{H} / k_{D} \\
\end{array}$ & Clustered product BR \\
\hline $\mathrm{F}^{-}\left(\mathrm{CH}_{3} \mathrm{OH}\right)+\left(\mathrm{CH}_{3}\right)_{3} \mathrm{CBr}$ & $6.48 \pm 0.24$ & 0.27 & $2.10 \pm 0.11$ & $0.82 \pm 0.04$ & $0.73 \pm 0.03$ & 0.15 \\
\hline $\mathrm{F}^{-}\left(\mathrm{CH}_{3} \mathrm{OH}\right)+\left(\mathrm{CD}_{3}\right)_{3} \mathrm{CBr}$ & $3.08 \pm 0.12$ & 0.13 & & $0.66 \pm 0.03$ & $0.62 \pm 0.02$ & 0.23 \\
\hline $\mathrm{F}^{-}\left(\mathrm{CH}_{3} \mathrm{OD}\right)+\left(\mathrm{CH}_{3}\right)_{3} \mathrm{CBr}$ & $7.92 \pm 0.08$ & 0.33 & $1.70 \pm 0.04$ & & & 0.26 \\
\hline $\mathrm{F}^{-}\left(\mathrm{CH}_{3} \mathrm{OD}\right)+\left(\mathrm{CD}_{3}\right)_{3} \mathrm{CBr}$ & $4.66 \pm 0.11$ & 0.20 & & & & 0.20 \\
\hline $\mathrm{F}^{-}\left(\mathrm{CD}_{3} \mathrm{OD}\right)+\left(\mathrm{CH}_{3}\right)_{3} \mathrm{CBr}$ & $8.82 \pm 0.15$ & 0.37 & $1.78 \pm 0.03$ & & & 0.12 \\
\hline $\mathrm{F}^{-}\left(\mathrm{CD}_{3} \mathrm{OD}\right)+\left(\mathrm{CD}_{3}\right)_{3} \mathrm{CBr}$ & $4.95 \pm 0.05$ & 0.21 & & & & 0.17 \\
\hline $\mathrm{F}^{-}\left(\mathrm{C}_{2} \mathrm{H}_{5} \mathrm{OH}\right)+\left(\mathrm{CH}_{3}\right)_{3} \mathrm{CBr}^{\mathrm{b}}$ & $3.58 \pm 0.05$ & 0.16 & $3.84 \pm 0.33$ & $0.66 \pm 0.06$ & $0.63 \pm 0.03$ & 0.59 \\
\hline $\mathrm{F}^{-}\left(\mathrm{C}_{2} \mathrm{H}_{5} \mathrm{OH}\right)+\left(\mathrm{CD}_{3}\right)_{3} \mathrm{CBr}^{\mathrm{b}}$ & $0.93 \pm 0.08$ & 0.042 & & $0.46 \pm 0.05$ & $0.44 \pm 0.04$ & 0.50 \\
\hline $\mathrm{F}^{-}\left(\mathrm{C}_{2} \mathrm{H}_{5} \mathrm{OD}\right)+\left(\mathrm{CH}_{3}\right)_{3} \mathrm{CBr}^{\mathrm{b}}$ & $5.39 \pm 0.05$ & 0.24 & $2.64 \pm 0.21$ & & & 0.58 \\
\hline $\mathrm{F}^{-}\left(\mathrm{C}_{2} \mathrm{H}_{5} \mathrm{OD}\right)+\left(\mathrm{CD}_{3}\right)_{3} \mathrm{CBr}^{\mathrm{b}}$ & $2.04 \pm 0.16$ & 0.09 & & & & 0.50 \\
\hline $\mathrm{F}^{-}\left(\mathrm{C}_{2} \mathrm{D}_{5} \mathrm{OD}\right)+\left(\mathrm{CH}_{3}\right)_{3} \mathrm{CBr}^{\mathrm{b}}$ & $5.67 \pm 0.04$ & 0.26 & $2.70 \pm 0.10$ & & & 0.48 \\
\hline $\mathrm{F}^{-}\left(\mathrm{C}_{2} \mathrm{D}_{5} \mathrm{OD}\right)+\left(\mathrm{CD}_{3}\right)_{3} \mathrm{CBr}^{\mathrm{b}}$ & $2.10 \pm 0.08$ & 0.098 & & & & 0.50 \\
\hline
\end{tabular}

aError bars for branching ratios are $\pm 30 \%$

${ }^{\mathrm{b}}$ Reactions of ethanol-solvated fluoride with t-butyl bromide produced an association product. Association branching fractions are $0.04,0.18,0.02$, $0.10,0.02$, and 0.07 respectively. Overall rate constants are $3.72 \times 10^{-10} \mathrm{~cm}^{3} \mathrm{~s}^{-1}, 1.13 \times 10^{-10} \mathrm{~cm}^{3} \mathrm{~s}^{-1}, 5.50 \times 10^{-10} \mathrm{~cm}^{3} \mathrm{~s}^{-1}, 2.27 \times 10^{-10} \mathrm{~cm}^{3} \mathrm{~s}^{-1}, 5.79 \times$ $10^{-10} \mathrm{~cm}^{3} \mathrm{~s}^{-1}$, and $2.26 \times 10^{-10} \mathrm{~cm}^{3} \mathrm{~s}^{-1}$, respectively. The contribution from association is subtracted from the observed rate constant to determine the E2 rate constant. While there appears to be variation in the association branching fractions, their ratios essentially cancel out in the kinetic isotope effects. That is, for the three kinetic isotope effects measured as a result of deuteration of the solvent, $0.04 \mathrm{k}_{\mathrm{H}} / 0.18 \mathrm{k}_{\mathrm{D}} \approx 0.02 \mathrm{k}_{\mathrm{H}} / 0.10 \mathrm{k}_{\mathrm{D}} \approx 0.02 \mathrm{k}_{\mathrm{H}} / 0.07 \mathrm{k}_{\mathrm{D}}$ The same is true of the solvent effects.

in this study should accurately reflect the difference in transition states between the perprotio and perdeutero reactants. The series of reactions of $t$-butyl bromide with $\mathrm{F}^{-}\left(\mathrm{CH}_{3} \mathrm{OH}\right)$ are more efficient than the series with $\mathrm{F}^{-}\left(\mathrm{C}_{2} \mathrm{H}_{5} \mathrm{OH}\right)$, and the isotope effects for the latter are more pronounced.

Isotope effects determined for reactions upon deuteration of the neutral reagent are significantly greater than one. This effect is attributed to the $\mathrm{C}-\mathrm{H}$ and $\mathrm{C}-\mathrm{D}$ bonds loosening in the E2 transition state (Figure 1). It is unlikely that there is a contribution from a competing $\mathrm{S}_{\mathrm{N}} 2$ mechanism; the $t$-butyl group has been shown to provide considerable steric hindrance which prevents an $S_{N} 2$ reaction from occurring [6]. Additionally, there is no evidence of a ligand switching mechanism in which the neutral reactant replaces the solvent in the cluster. This mechanism is endothermic due to the strong interaction between the fluoride anion and the solvent molecule. $\mathrm{F}^{-}\left(\mathrm{CH}_{3} \mathrm{OH}\right)$ and $\mathrm{F}^{-}\left(\mathrm{C}_{2} \mathrm{H}_{5} \mathrm{OH}\right)$ are bound by $124 \mathrm{~kJ}$ $\mathrm{mol}^{-1}$ and $135.6 \mathrm{~kJ} \mathrm{~mol}^{-1}$, respectively; in contrast, the cluster bond energy of $\mathrm{F}^{-}\left(\left(\mathrm{CH}_{3}\right)_{3} \mathrm{CBr}\right)$ is estimated to be $106 \mathrm{~kJ} \mathrm{~mol}^{-1}$. Furthermore, the detection of an appre- ciable amount of $\mathrm{Br}^{-}(\mathrm{HF})$ clusters provides direct evidence of the occurrence of an E2 mechanism.

Isotope effects determined as a result of deuteration of the solvent are inverse. Generally, the solvent isotope effect is attributed to a shrinking of a bond within the solvent molecule, in this case the $\mathrm{O}-\mathrm{H}$ bond, as the reaction proceeds from the reactants to the transition state. In the reactants, the $\mathrm{O}-\mathrm{H}$ bond is elongated relative to that in an isolated solvent molecule, due to its interaction with fluoride. As the reaction proceeds, this interaction weakens and the $\mathrm{O}-\mathrm{H}$ bond contracts.

The solvent isotope effects are more pronounced for the reactions of $\mathrm{F}^{-}\left(\mathrm{C}_{2} \mathrm{H}_{5} \mathrm{OH}\right)$ than for the reactions of $\mathrm{F}^{-}\left(\mathrm{CH}_{3} \mathrm{OH}\right)$; both of these solvent isotope effects are more dramatic than that observed for $\mathrm{F}^{-}\left(\mathrm{H}_{2} \mathrm{O}\right)$, which was 0.94 for the reaction with $t$-butyl bromide. This trend reflects the acidities of the solvent, and therefore the cluster binding energy. Ethanol is the most acidic of these solvents and therefore most readily shares a proton with fluoride. The stronger the interaction between fluoride and the solvent molecule, the more elongated the $\mathrm{O}-\mathrm{H}$ bond becomes, relative to the iso-

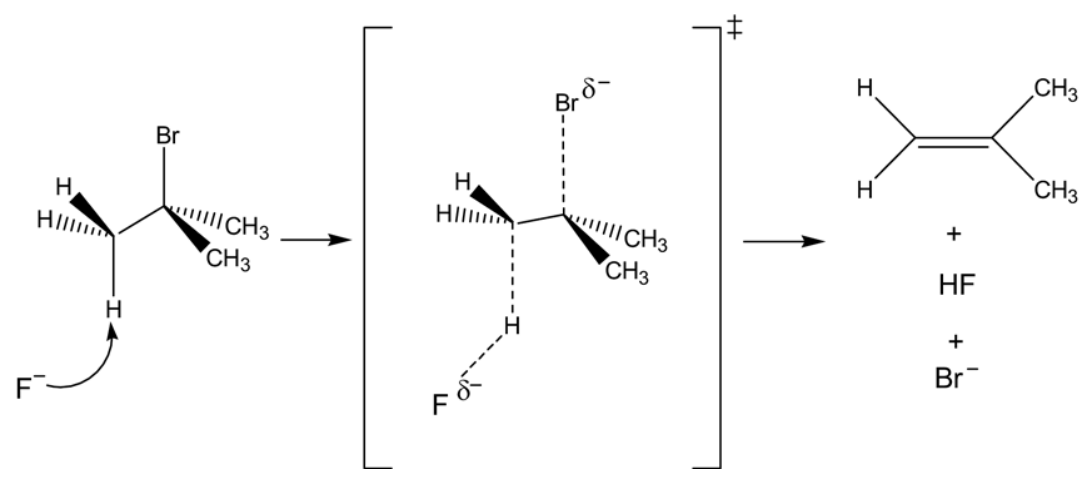

Figure 1. Elimination mechanism for the reaction of $\mathrm{F}^{-}$with $t$-butyl bromide. 
lated solvent molecule. As the reaction proceeds, the $\mathrm{O}-\mathrm{H}$ bond in the $\mathrm{F}^{-}\left(\mathrm{C}_{2} \mathrm{H}_{5} \mathrm{OH}\right)$ cluster changes the most significantly in returning to its "isolated" geometry.

We have previously studied the kinetic isotope effects for a wide variety of microsolvated substitution reactions. These results also demonstrate an inverse KIE upon deuteration of the solvent. Figure 2 shows the solvent kinetic isotope effects as a function of reaction efficiency for the previously studied $\mathrm{S}_{\mathrm{N}} 2$ reactions of $\mathrm{F}^{-}\left(\mathrm{H}_{2} \mathrm{O}\right)$ and $\mathrm{F}^{-}\left(\mathrm{CH}_{3} \mathrm{OH}\right)$ with methyl bromide [19], as well as the E2 reactions of $\mathrm{F}^{-}\left(\mathrm{H}_{2} \mathrm{O}\right)$ [27], $\mathrm{F}^{-}\left(\mathrm{CH}_{3} \mathrm{OH}\right)$ and $\mathrm{F}^{-}\left(\mathrm{C}_{2} \mathrm{H}_{5} \mathrm{OH}\right)$ with $t$-butyl bromide. This plot demonstrates that the KIEs approach unity as the reaction efficiency increases.

Theoretical studies of $S_{N} 2$ reactions have shown that for exothermic systems the solvent remains attached to the anion through the transition state [23, 29, 38], whereas for thermoneutral reactions the solvent likely does not remain bound [25, 39]. The $\mathrm{S}_{\mathrm{N}} 2$ reactions shown in Figure 2 are more exothermic than those in the theoretical studies, and therefore likely the anion remains solvated. While these computational results may seem inconsistent with thermochemical considerations, it may reflect that earlier transition states can occur for more exothermic reactions. The $S_{N} 2$ reactions and the E2 reactions shown here follow similar trends; this suggests that these elimination reactions also pro-

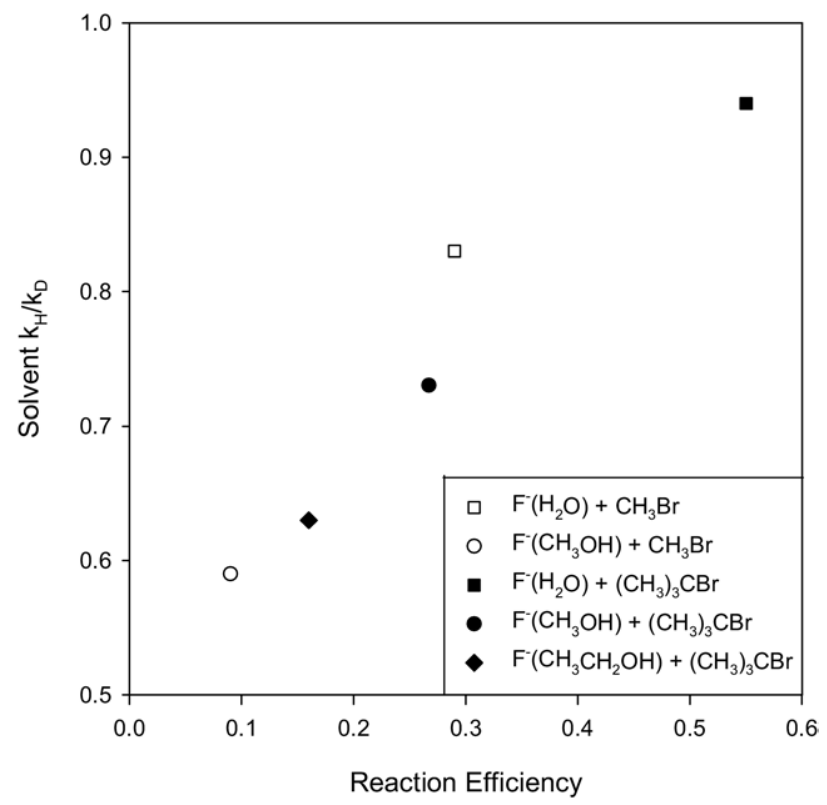

Figure 2. Solvent kinetic isotope effects as a function of reaction efficiency for $\mathrm{S}_{\mathrm{N}} 2$ and E2 microsolvated reactions for alkyl bromides. The solid symbols represent elimination reactions and open symbols represent substitution reactions. From reference [28]: $\mathrm{F}^{-}+\mathrm{CH}_{3} \mathrm{Br}, \mathrm{k}=1.88 \times 10^{-9}$ (efficiency $\left.=0.70\right) \Delta \mathrm{H}_{\mathrm{rxn}}-168$ $\mathrm{kJ} \mathrm{mol}^{-1} ; \mathrm{F}^{-}\left(\mathrm{H}_{2} \mathrm{O}\right)+\mathrm{CH}_{3} \mathrm{Br}, \mathrm{k}=4.97 \times 10^{-10}$ (efficiency $=0.29$ ) $\Delta \mathrm{H}_{\mathrm{rxn}}=-75 \mathrm{~kJ} \mathrm{~mol}^{-1}$. From ref 19: $\mathrm{F}^{-}\left(\mathrm{CH}_{3} \mathrm{OH}\right)+\mathrm{CH}_{3} \mathrm{Br}, \mathrm{k}=$ $1.6 \times 10^{-9}$ (efficiency $\left.=0.09\right) \Delta \mathrm{H}_{\mathrm{rxn}}=-41 \mathrm{~kJ} \mathrm{~mol}^{-1}$. From ref 27: $\mathrm{F}^{-}+\left(\mathrm{CH}_{3}\right)_{3} \mathrm{CBr} \mathrm{k}=2.58 \times 10^{-9}($ efficiency $=0.71) \Delta \mathrm{H}_{\mathrm{rxn}}=-127$ $\mathrm{kJ} \mathrm{mol}{ }^{-1} ; \mathrm{F}^{-}\left(\mathrm{H}_{2} \mathrm{O}\right)+\left(\mathrm{CH}_{3}\right)_{3} \mathrm{CBr}, \mathrm{k}=1.50 \times 10^{-9}$ (efficiency $=$ 0.55) $\Delta \mathrm{H}_{\mathrm{rxn}}=-14 \mathrm{~kJ} \mathrm{~mol}^{-1}$. ceed though a transition state where the solvent is bound to the anion.

The reaction efficiencies for bare fluoride with methyl bromide (an $\mathrm{S}_{\mathrm{N}} 2$ reaction) and with $t$-butyl bromide (an E2 reaction) are 0.70 and 0.71 , respectively. When one compares the efficiencies and KIEs for the reactions of water-solvated fluoride with these two neutral reagents, shown in Figure 2, the $S_{N} 2$ reaction has become significantly less efficient than the E2 reaction despite being the more exothermic of the reactions. The same is true for the reactions of methanol-solvated fluoride. These observations were not expected since computations have shown that solvation stabilizes $S_{N} 2$ transition states relative to E2 transition states [18]. However, this is the first study that directly compares bare $\mathrm{S}_{\mathrm{N}} 2$ and $\mathrm{E} 2$ systems and solvated $\mathrm{S}_{\mathrm{N}} 2$ and E2 systems experimentally. This intriguing result is a clear target for future experimental and theoretical work.

There have been several attempts [40-42] to define parameters that relate transition-state geometry to reactivity and isotope effects for $S_{N} 2$ reactions In an $S_{N} 2$ reaction, the nucleophile attacks a tetrahedral molecule $180^{\circ}$ away from the leaving group; a trigonal planar transition state is formed before expelling the leaving group to form a tetrahedral molecule that is inverted relative to the original molecule. Most recently, Glad and Jensen [42] defined a looseness parameter, $\Delta \mathrm{R}^{\ddagger}$ :

$$
\begin{aligned}
& \Delta \mathrm{R}_{\mathrm{CX}}^{\ddagger}=\mathrm{R}_{\mathrm{CX}}^{\ddagger}-\mathrm{R}_{\mathrm{CX}}^{0} \\
& \Delta \mathrm{R}^{\ddagger}=\Delta \mathrm{R}_{\mathrm{CNu}}^{\ddagger}+\Delta \mathrm{R}_{\mathrm{CL}}^{\ddagger}
\end{aligned}
$$

where the superscript zero refers to the reactant or product bond length, the superscript dagger refers to the transition state, and $X$ refers to either the nucleophile $(\mathrm{Nu})$ or the leaving group (L). The looseness parameter is therefore the sum of the changes in bond length as the reaction proceeds. As the looseness parameter increases, the kinetic isotope effect increases (becomes less inverse). In addition to transition-state "looseness", $\mathrm{S}_{\mathrm{N}} 2$ transition states have also recently been discussed as a function of transition-state "crowdedness." $\mathrm{S}_{\mathrm{N}} 2$ deuterium KIEs are mostly a result of $\mathrm{C}-\mathrm{H}$ stretching and out-of-plane bending motions; the space available to these motions is therefore crucial, but not necessarily proportional to the looseness of the transition state. However, no explicit parameter has been defined to address the volumes occupied by the attacking nucleophile and the corresponding transition state; only qualitative arguments of analogous systems have been made.

No such parameters have been suggested for E2 reactions possibly due to difficulties in accurately calculating E2 transition-state geometries. We have calculated analogues to the above parameter for the E2 transition-state geometry, as shown in Table 2, for the reactions of microsolvated fluoride ion with $t$-butyl bromide for the E2 systems presented in this work, $\Delta \mathrm{R}^{\ddagger}$ is the sum of the changes in bond lengths (labeled 1-3 in 
Table 2. Transition state looseness parameter

\begin{tabular}{rcc}
\hline Reaction & KIE & $\Delta R^{\mp}$ \\
\hline \hline $\mathrm{F}^{-}\left(\mathrm{H}_{2} \mathrm{O}\right)+\left(\mathrm{CH}_{3}\right)_{3} \mathrm{CBr}$ & 1.21 & 0.706 \\
$\mathrm{~F}^{-}\left(\mathrm{CH}_{3} \mathrm{OH}\right)+\left(\mathrm{CH}_{3}\right)_{3} \mathrm{CBr}$ & 2.10 & 0.726 \\
$\mathrm{~F}^{-}\left(\mathrm{C}_{2} \mathrm{H}_{5} \mathrm{OH}\right)+\left(\mathrm{CH}_{3}\right)_{3} \mathrm{CBr}$ & 3.82 & 0.740 \\
\hline
\end{tabular}



Figure 3. Schematic of transition state, specifically labeling bonds used to calculate looseness parameters shown in Table 2 .

Figure 3) between reactants and transition state, which are expected to change significantly as an elimination mechanism proceeds. Normal KIEs for deuteration of the neutral reactant in an $\mathrm{E} 2$ reaction are mostly due to a change in the $\mathrm{C}-\mathrm{H}_{\beta}$ stretching motion. This $\mathrm{C}-\mathrm{H}$ motion likely would not be affected by crowdedness, but instead by the looseness of the transition state. The crowdedness of the transition state, however, may affect the separability of the isotope effects and will be discussed later. As shown in Table 2, the looseness parameter increases as the kinetic isotope effect increases, consistent with our results. In an analogous manner to the $\mathrm{S}_{\mathrm{N}} 2$ systems, this parameter provides an accurate description of the reaction coordinate. While our optimized geometries correlate well with measured kinetic isotope effects, it is not possible to use these calculations to predict computational energetics since it is difficult to determine activation enthalpies to within $2 \mathrm{~kJ} \mathrm{~mol}^{-1}$ [43]; in addition elimination reactions have a large number of low-frequency modes which are difficult to calculate.

For our previously studied microsolvated reactions (both $\mathrm{S}_{\mathrm{N}} 2$ and E2), the KIE as a result of deuterating the solvent and the KIE as a result of deuterating the neutral reagent were separable to a first-order approximation. That is, for example:

$$
\begin{aligned}
& K I E=\frac{k\left[F^{-}\left(\mathrm{H}_{2} \mathrm{O}\right)+\left(\mathrm{CH}_{3}\right)_{3} \mathrm{CBr}\right]}{k\left[F^{-}\left(\mathrm{D}_{2} \mathrm{O}\right)+\left(\mathrm{CD}_{3}\right)_{3} \mathrm{CBr}\right]} \\
& \approx \frac{k\left[F^{-}\left(\mathrm{H}_{2} \mathrm{O}\right)+\left(\mathrm{CH}_{3}\right)_{3} \mathrm{CBr}\right]}{k\left[F^{-}\left(\mathrm{H}_{2} \mathrm{O}\right)+\left(\mathrm{CD}_{3}\right)_{3} \mathrm{CBr}\right]} \times \frac{k\left[F^{-}\left(\mathrm{H}_{2} \mathrm{O}\right)+\left(\mathrm{CH}_{3}\right)_{3} \mathrm{CBr}\right]}{k\left[F^{-}\left(\mathrm{D}_{2} \mathrm{O}\right)+\left(\mathrm{CH}_{3}\right)_{3} \mathrm{CBr}\right]}
\end{aligned}
$$

However, in the cases of $\mathrm{F}^{-}\left(\mathrm{CH}_{3} \mathrm{OH}\right)$ and $\mathrm{F}^{-}\left(\mathrm{C}_{2} \mathrm{H}_{5} \mathrm{OH}\right)$, the analogous equality does not hold.
For $\mathrm{F}^{-}\left(\mathrm{CH}_{3} \mathrm{OH}\right)$, the overall observed $\mathrm{KIE}$ is 1.31 whereas the product of the individual isotope effects predicts the overall KIE to be 1.55 , slightly outside of the experimental error. For the reaction of $\mathrm{F}^{-}\left(\mathrm{C}_{2} \mathrm{H}_{5} \mathrm{OH}\right)$ the overall observed $\mathrm{KIE}$ is 1.71 while the product of the individual isotope effects predicts an overall KIE of 2.42, well outside of the experimental error. This is not surprising when one carefully examines the isotope effects. Consider, for example, the reactions of methanol-solvated fluoride with $t$-butyl bromide when deuteration occurs only at the alcohol functional group. The isotope effect observed for reaction with $\left(\mathrm{CH}_{3}\right)_{3} \mathrm{CBr}$ is 0.82. However, when the neutral reactant is $\left(\mathrm{CD}_{3}\right)_{3} \mathrm{CBr}$, the isotope effect is 0.66 , a $20 \%$ decrease! The isotopic composition of the neutral reagent affects the solvent kinetic isotope effect.

$\mathrm{Hu}$ and Truhlar [29] calculated the isotope effects for the $\mathrm{S}_{\mathrm{N}} 2$ reaction of $\mathrm{F}^{-}\left(\mathrm{H}_{2} \mathrm{O}\right)$ with $\mathrm{CH}_{3} \mathrm{Cl}$. They noted two unexpected normal modes that were a positive and negative linear combination of the $\mathrm{CH}_{3} \mathrm{Cl}$ methyl group internal rotation and the out-of-plane bending motion of the free $\mathrm{O}-\mathrm{H}$. These modes were the most isotopically sensitive low-frequency modes, and therefore large contributors to the inverse isotope effect. Kato et al. [19] suggested that an analogous mode was present in the transition state of the reaction of $\mathrm{F}^{-}\left(\mathrm{CH}_{3} \mathrm{OH}\right)+$ $\mathrm{CH}_{3} \mathrm{X}$, where $\mathrm{X}=\mathrm{Br}$ and $\mathrm{I}$, since deuteration of the methyl group in methanol resulted in an inverse KIE. Certainly, modes exist in these elimination transition states that involve motion of the solvent and motion of the neutral reagent, and therefore the isotopic composition of both the neutral reagent and the solvent contribute in some way to each isotope effect.

A physical interaction or conformational effect between the solvent and the neutral reagent at the transition state is also likely. Let us consider the two extremes as shown in Figure 4. In Figure 4a, the ethanol solvent lies below the $t$-butyl bromide offering little opportunity for a physical interaction with the neutral reagent;

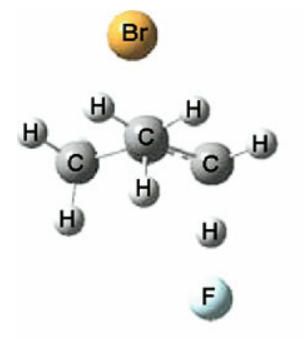

(a)


Figure 4. Transition state for the reaction of $\mathrm{F}^{-}\left(\mathrm{C}_{2} \mathrm{H}_{5} \mathrm{OH}\right)$ with $t$-butyl bromide where (a) there is less crowding and there is limited physical interaction between the solvent and the neutral reagent, and (b) where there is more crowding and more physical interaction between the solvent and the neutral reagent. 
this represents a less crowded transition state. In Figure $4 \mathrm{~b}$, the ethanol solvent lies adjacent to the $t$-butyl bromide, representing a more crowded transition state. The difference in these two structures is essentially the $\mathrm{HFHO}$ dihedral angle, which involves the rotation of the ethyl group around the oxygen. Likely, there is a low barrier to rotation for this angle. This situation is analogous to the looseness or space afforded to particular vibrations for $\mathrm{S}_{\mathrm{N}} 2$ reactions. For fundamental modes, which include motion of both the $t$-butyl group and the solvent molecule, the space available for each motion is critical. Changing the isotopic composition of either the $t$-butyl group or the solvent molecule will affect the vibrational frequencies. If the transition state resembles Figure $4 b$, changing the vibrational frequencies of a part of the structure may affect the rest of the complex.

It is important to note, however, that while these effects are not completely separable, the magnitude and direction of the effects are consistent with previous explanations. That is, the normal isotope effect upon deuteration of the neutral reagent is mostly a result of the lengthening of the $\mathrm{C}-\mathrm{H}$ bond in the transition state; the inverse isotope effect observed as a result of deuteration of the solvent molecule is a result of the water $\mathrm{O}-\mathrm{H}$ bond length shrinking. Calculations further confirm that the bond lengths and angles change in accord with the previous assignments. The bond length within the solvent molecule does indeed decrease from reactants to transition state, and bond lengths and angles within the E2 transition-state change as have been seen for other calculated transition states.

Surprisingly, all of the microsolvated isotope effects that have been measured in the past were found to be separable. For the previously studied elimination systems, this is likely due to the size of the reactant. While the neutral reagent in these reactions was also a $t$-butyl halide, the solvent molecule was water. It is unlikely that water could provide much crowding of a $t$-butyl halide. For $\mathrm{S}_{\mathrm{N}} 2$ systems, crowding of the transition state does not affect separability, but instead directly affects the neutral reagent isotope effect as discussed above.

The reaction of $\mathrm{F}^{-}\left(\mathrm{CH}_{3} \mathrm{OH}\right)$ with $t$-butyl bromide produces $\mathrm{Br}^{-}$as the major product, minor amounts of $\mathrm{Br}^{-}(\mathrm{HF})$, and trace amounts of $\mathrm{Br}^{-}\left(\mathrm{CH}_{3} \mathrm{OH}\right)$. The reaction of $\mathrm{F}^{-}\left(\mathrm{C}_{2} \mathrm{H}_{5} \mathrm{OH}\right)$ with $t$-butyl bromide produces similar amounts of $\mathrm{Br}^{-}$and $\mathrm{Br}^{-}(\mathrm{HF})$, as well as minor amounts of $\mathrm{Br}^{-}\left(\mathrm{C}_{2} \mathrm{H}_{5} \mathrm{OH}\right)$. While clearly entropic factors will favor the production of unclustered products, these contributions are likely small. The overall energetics of these reactions, as shown in Table 3, are dominated by enthalpy contributions and suggest that the formation of clustered products will dominate the product distribution.

Calculations show that transition states for elimination reactions that have the anti-periplanar geometry are energetically favored over those with syn-periplanar geometry. If the product dynamics are more direct than statistical, this transition-state geometry may hinder the
Table 3. Reaction exothermicities

\begin{tabular}{clc}
\hline \multicolumn{1}{c}{ Reaction } & Ionic product & $\Delta \mathrm{H}_{\mathrm{rxn}}(\mathrm{kJ} / \mathrm{mol})^{\mathrm{a}}$ \\
\hline \hline $\mathrm{F}^{-}\left(\mathrm{CH}_{3} \mathrm{OH}\right)+\left(\mathrm{CH}_{3}\right)_{3} \mathrm{CBr}$ & $\mathrm{Br}^{-}$ & -3.3 \\
& $\mathrm{Br}^{-}\left(\mathrm{CH}_{3} \mathrm{OH}\right)$ & -64.0 \\
& $\mathrm{Br}^{-}(\mathrm{HF})$ & -74.5 \\
$\mathrm{~F}^{-}\left(\mathrm{C}_{2} \mathrm{H}_{5} \mathrm{OH}\right)+\left(\mathrm{CH}_{3}\right)_{3} \mathrm{CBr}$ & $\mathrm{Br}^{-}$ & 8.4 \\
& $\mathrm{Br}^{-}\left(\mathrm{C}_{2} \mathrm{H}_{5} \mathrm{OH}\right)$ & -50.6 \\
& $\mathrm{Br}^{-}(\mathrm{HF})$ & -62.8
\end{tabular}

aData to determine $\Delta \mathrm{H}_{\mathrm{rxn}}$ were taken from the JANAF Thermochemical Tables [44] or the NIST WebBook [45]

formation of clusters as a major product. The $t$-butyl group lies between the leaving halide and the newly formed elimination product, sterically hindering the formation of the clusters.

The unsolvated $\mathrm{Br}^{-}$is the dominant product of the reaction of $\mathrm{F}^{-}\left(\mathrm{CH}_{3} \mathrm{OH}\right)$ with $t$-butyl bromide. The reaction of $\mathrm{F}^{-}\left(\mathrm{C}_{2} \mathrm{H}_{5} \mathrm{OH}\right)$ with $t$-butyl bromide produces slightly more $\mathrm{Br}^{-}$than $\mathrm{Br}^{-}(\mathrm{HF})$. The preference to form bare anions and the varied distribution of clustered products is probably due to product dynamics in the post-transition-state reaction complex; these complexes may be long-lived since these reactions are only moderately exothermic. This suggestion is consistent with the fact that the less exothermic $\mathrm{F}^{-}\left(\mathrm{C}_{2} \mathrm{H}_{5} \mathrm{OH}\right)$ reactions form more clustered products than the reactions of $\mathrm{F}^{-}\left(\mathrm{CH}_{3} \mathrm{OH}\right)$, and that the $\mathrm{F}^{-}\left(\mathrm{CH}_{3} \mathrm{OH}\right)$ reactions produce more clustered products than were observed for the $\mathrm{F}^{-}\left(\mathrm{H}_{2} \mathrm{O}\right)$ reactions.

\section{Conclusions}

The reactions of $\mathrm{F}^{-}\left(\mathrm{CH}_{3} \mathrm{OH}\right)$ and $\mathrm{F}^{-}\left(\mathrm{C}_{2} \mathrm{H}_{5} \mathrm{OH}\right)$ with $t$-butyl bromide are examined with deuterium labeling, and more pronounced isotope effects are measured than for the corresponding reactions of $\mathrm{F}^{-}\left(\mathrm{H}_{2} \mathrm{O}\right)$. Normal isotope effects observed as a result of deuterating the neutral reagent are indicative of an E2 reaction. Inverse isotope effects observed as a result of deuterating the solvent are due to the reactant ion being more strongly solvated than the transition state. These effects are not completely separable, probably due to a physical interaction of the $t$-butyl group and the solvent molecule in the transition state. The use of a "looseness" parameter provides good correlations of the transition-state geometries to the E2 kinetic isotope effects.

\section{Acknowledgments}

The authors thank Professor Charles H. DePuy for helpful discussions and support from the National Science Foundation (CHE0647088). The authors acknowledge that this research was supported in part by the National Science Foundation through TeraGrid resources provided by NCSA [46].

\section{References}

1. McMurry, J. Organic Chemistry, 5th ed.; Brooks-Cole: Pacific Grove, 1999. 
2. Lowry, T. H.; Schueller Richardson, K., Eds., Mechanism and Theory in Organic Chemistry, 3rd ed.; Harper and Row: New York, 1987.

3. Gronert, S. Mass Spectrometric Studies of Organic Ion/Molecule Reactions. Chem. Rev. 2001, 101, 329-360.

4. Takashima, K.; Riveros, J. M. Gas-Phase Solvated Negative Ions. Mass Spectrom. Rev. 1999, 17, 409-430.

5. Wladkowski, B. D.; Brauman, J. I. Substitution Versus Elimination in Gas-Phase Ionic Reactions. J. Am. Chem. Soc. 1992, 114, 10643-10644.

6. DePuy, C. H.; Gronert, S.; Mullin, A.; Bierbaum, V. M. Gas-Phase $\mathrm{S}_{\mathrm{N}} 2$ and E2 Reactions of Alkyl Halides. J. Am. Chem. Soc. 1990, 112, $8650-8655$

7. Villano, S. M.; Kato, S.; Bierbaum, V. M. Deuterium Kinetic Isotope Effects in Gas-Phase $\mathrm{S}_{\mathrm{N}} 2$ and E2 Reactions: Comparison of Experiment and Theory. J. Am. Chem. Soc. 2006, 128, 736-737.

8. Gronert, S. Nucleophilic Substitution and Elimination Reactions. In The Encyclopedia of Mass Spectrometry, Armentrout, P. B., Ed.; Elsevier: New York, 2003; pp. 643-647.

9. O'Hair, R. A. J. $\mathrm{S}_{\mathrm{N}} 2$ and Related Reactions. In The Encyclopedia of Mass Spectrometry; Armentrout, P. B., Ed.; Elsevier: New York, 2003; pp. $604-618$

10. Bohme, D. K.; Mackay, G. I.; Payzant, J. D. Activation-Energies in Nucleophilic Displacement-Reactions Measured at 296 Degrees K in Vacuo. J. Am. Chem. Soc. 1974, 96, 4027-4028.

11. Damrauer, R.; Depuy, C. H.; Bierbaum, V. M. Reactions of Trimethylchlorosilane with Various Nucleophiles in the Gas-Phase Using the Flowing Afterglow Technique. Organometallics 1982, 1, 1553-1554.

12. Edwards, J. O.; Pearson, R. G. Factors Determining Nucleophilic Reactivities. J. Am. Chem. Soc. 1962, 84, 16-24.

13. Tanaka, K.; Mackay, G. I.; Payzant, J. D.; Bohme, D. K. Gas-Phase Reactions of Anions with Halogenated Methanes at $297 \pm 2$ K. Can J. Chem. 1976, 54, 1643-1659.

14. Young, L. B.; Lee-Ruff, E.; Bohme, D. K. Gas-Phase Nucleophilicities of Anions- $\mathrm{H}^{-}, \mathrm{F}^{-}, \mathrm{OH}^{-}$, and $\mathrm{NH}_{2}^{-}$. J. Chem. Soc., Chem. Commun. 1973, 35-36.

15. Taft, R. W. Protonic Acidities and Basicities in the Gas Phase and in Solution: Substituent and Solvent Effects. Prog. Phys. Org. Chem. 1983, 14, 247-350.

16. Brauman, J. I.; Blair, L. K. Gas-Phase Acidities of Alcohols. J. Am. Chem. Soc. 1970, 92, 5986-5992.

17. Bohme, D. K.; Mackay, G. I. Bridging the Gap Between the Gas-Phase and Solution Transition in the Kinetics of Nucleophilic DisplacementReactions. J. Am. Chem. Soc. 1981, 103, 978-979.

18. Bickelhaupt, F. M.; Baerends, E. J.; Nibbering, N. M. M. The Effect of Microsolvation on E2 and $\mathrm{S}_{\mathrm{N}} 2$ Reactions: Theoretical Study of the Model System $\mathrm{F}^{-}+\mathrm{C}_{2} \mathrm{H}_{5} \mathrm{~F}+n \mathrm{HF}$. Chem. Eur. J. 1996, 2, 196-207.

19. Kato, S.; Hacaloglu, J.; Davico, G. E.; DePuy, C. H.; Bierbaum, V. M. Deuterium Kinetic Isotope Effects in the Gas-Phase $\mathrm{S}_{\mathrm{N}} 2$ Reactions of Solvated Fluoride Ions with Methyl Halides. J. Phys. Chem. A 2004, 108, 9887-9891.

20. Seeley, J. V.; Morris, R. A.; Viggiano, A. A. Temperature Dependencies of the Rate Constants and Branching Ratios for the Reactions of $\mathrm{F}^{-}\left(\mathrm{H}_{2} \mathrm{O}\right)_{0-5}$ with $\mathrm{CH}_{3}$ Br. J. Phys. Chem. A 1997, 101, 4598-4601.

21. Wu, Y.-R.; Hu, W.-P. Reaction Dynamics Study on the Tunneling Effects of a Microsolvated E2 Reaction: $\mathrm{FO}^{-}\left(\mathrm{H}_{2} \mathrm{O}\right)+\mathrm{C}_{2} \mathrm{H}_{5} \mathrm{Cl} \rightarrow \mathrm{HOF}\left(\mathrm{H}_{2} \mathrm{O}\right)+$ $\mathrm{C}_{2} \mathrm{H}_{4}+\mathrm{Cl}^{-}$. J. Am. Chem. Soc. 1999, 121, 10168-10177.

22. Thomas, J. M.; Viggiano, A. A. Kinetics for the Reactions of $\mathrm{H}_{3} \mathrm{O}^{+}\left(\mathrm{H}_{2} \mathrm{O}\right)_{n}$ with $\mathrm{CH}_{3} \mathrm{SOCH}_{3}$. J. Phys. Chem. A 1999, 103, 2720-2722.

23. Ohta, K.; Morokuma, K. An MO Study of $\mathrm{S}_{\mathrm{N}} 2$ Reactions in Hydrated Gas Clusters- $\left(\mathrm{H}_{2} \mathrm{O}\right)_{n} \mathrm{OH}^{-}+\mathrm{CH}_{3} \mathrm{Cl}\left(\mathrm{H}_{2} \mathrm{O}\right)_{\mathrm{m}}^{-}->\mathrm{HOCH}_{3}+\mathrm{Cl}^{-}+$ $(\mathrm{n}+\mathrm{m}) \mathrm{H}_{2} \mathrm{O}$. J. Phys. Chem. 1985, 89, 5845-5849.

24. Hierl, P. M.; Ahrens, A. F.; Henchman, M. J.; Viggiano, A. A.; Paulson, J. F.; Clary, D. C. Chemistry as a Function of Solvation NumberSolvated Ion Reactions in the Gas Phase and Comparison with Solution. Faraday Discuss. Chem. Soc. 1988, 85, 37-51.

25. Tucker, S. C.; Truhlar, D. G. Effect of Nonequilibrium Solvation on Chemical Reaction Rate -Variational Transition State Theory Studies of the Microsolvated Reaction $\mathrm{Cl}^{-}\left(\mathrm{H}_{2} \mathrm{O}\right)_{\mathrm{n}}+\mathrm{CH}_{3} \mathrm{Cl}$. J. Am. Chem. Soc. 1990, 112, 3347-3361.

26. Viggiano, A. A.; Arnold, S. T.; Morris, R. A.; Ahrens, A. F.; Hierl, P. M. Temperature Dependences of the Rate Constants and Branching Ratios for the Reactions of $\mathrm{OH}^{-}\left(\mathrm{H}_{2} \mathrm{O}\right)_{0-4}+\mathrm{CH}_{3} \mathrm{Br}$. J. Phys. Chem. 1996, 100, 14397-14402.

27. Eyet, N.; Villano, S. M.; Kato, S.; Bierbaum, V. M. Deuterium Kinetic Isotope Effects in Microsolvated Gas-Phase E2 Reactions. J. Am. Soc. Mass Spectrom. 2007, 18, 1046-1051.
28. O'Hair, R. A. J.; Davico, G. E.; Hacaloglu, J.; Dang, T. T.; DePuy, C. H.; Bierbaum, V. M. Measurements of Solvent and Secondary Kinetic Isotope Effects for the Gas-Phase $\mathrm{S}_{\mathrm{N}} 2$ Reactions of Fluoride with Methyl Halides. J. Am. Chem. Soc. 1994, 116, 3609-3610.

29. Hu, W.-P.; Truhlar, D. G. Modeling Transition State Solvation at the Single-Molecule Level: Test of Correlated ab initio Predictions Against Experiment for the Gas-Phase $\mathrm{S}_{\mathrm{N}} 2$ Reaction of Microhydrated Fluoride with Methyl Chloride. J. Am. Chem. Soc. 1994, 116, 7797-7800.

30. Davico, G. E. Interpretation of the Gas-Phase Solvent Deuterium Kinetic Isotope Effects in the $\mathrm{S}_{\mathrm{N}} 2$ Reaction Mechanism: Comparison of Theoretical and Experimental Results in the Reaction of Microsolvated Fluoride Ions with Methyl Halides. J. Phys. Chem. A 2006, 110, 1311213121.

31. Van Doren, J. M.; Barlow, S. E.; DePuy, C. H.; Bierbaum, V. M. The Tandem Flowing Afterglow-SIFT-Drift. Int. J. Mass Spectrom. Ion Processes $1987,81,85-100$.

32. Bierbaum, V. M. Flow Tubes. In Encyclopedia of Mass Spectrometry; Armentrout, P. B., Ed.; Elsevier: New York, 2003; 98-108.

33. Frisch, M. J.; Trucks, G. W.; Schlegel, H. B.; Scuseria, G. E.; Robb, M. A.; Cheeseman, J. R.; Montgomery, J. J. A.; Vreven, T.; Kudin, K. N.; Burant, J. C.; Millam, J. M.; Iyengar, S. S.; Tomasi, J.; Barone, V.; Mennucci, B.; Cossi, M.; Scalmani, G.; Rega, N.; Petersson, G. A.; Nakatsuji, H.; Hada, M.; Ehara, M.; Toyota, K.; Fukuda, R.; Hasegawa, J.; Ishida, M.; Nakajima, T.; Honda, Y.; Kitao, O.; Nakai, H.; Klene, M.; Li, X.; Knox J. E.; Hratchian, H. P.; Cross, J. B.; Bakken, V.; Adamo, C.; Jaramillo, J.; Gomperts, R.; Stratmann, R. E.; Yazyev, O.; Austin, A. J.; Cammi, R.; Pomelli, C.; Ochterski, J. W. A., P. Y.; Morokuma, K.; Voth, G. A.; Salvador, P.; Dannenberg, J. J.; Zakrzewski, V. G.; Dapprich, S.; Daniels, A. D.; Strain, M. C.; Farkas, O.; Malick, D. K.; Rabuck, A. D.; Raghavachari, K.; Foresman, J. B.; Ortiz, J. V.; Cui, Q.; Baboul, A. G.; Clifford, S. Cioslowski, J.; Stefanov, B. B.; Liu, G.; Liashenko, A.; Piskorz, P.; Komaromi, I.; Martin, R. L.; Fox, D. J.; Keith, T.; Al-Laham, M. A.; Peng, C. Y.; Nanayakkara, A.; Challacombe, M.; Gill, P. M. W.; Johnson, B. Chen, W.; Wong, M. W.; Gonzalez, C.; Pople, J. A. Gaussian 03, Revision D.01; Gaussian, Inc., Pittsburgh, PA, 2004.

34. Becke, A. D. Density-Functional Thermochemistry. III. The Role of Exact Exchange. J. Chem. Phys. 1993, 98, 5648-5652.

35. Lee, C.: Yang, W. T.; Parr, R. G. Development of the Colle-Salvetti Correlation-Energy Formula into a Functional of the Electron Density. Phys. Rev. B 1988, 37, 785-789.

36. Su, T.; Chesnavich, W. J. Parameterization of the Ion-Polar Molecule Collision Rate Constant by Trajectory Calculations. J. Chem. Phys. 1982, 76, 5183-5185.

37. Miller, K. J.; Savchik, J. A New Empirical Method to Calculate Average Molecular Polarizabilities. J. Am. Chem. Soc. 1979, 101, 7206-7213.

38. Tachikawa, H. Collision Energy Dependence on the Microsolvated $\mathrm{S}_{\mathrm{N}} 2$ Reaction of $\mathrm{F}^{-}\left(\mathrm{H}_{2} \mathrm{O}\right)$ with $\mathrm{CH}_{3} \mathrm{Cl}$ : A Full Dimensional ab Initio Direct Dynamics Study. J. Phys. Chem. A 2001, 105, 1260-1266.

39. Morokuma, K. Potential-Energy Surface of the $S_{N} 2$ Reaction in Hydrated Clusters. J. Am. Chem. Soc. 1982, 104, 3732-3733.

40. Wolfe, S.; Kim, C. K. Secondary H/D Isotope Effects in Methyl-Transfer Reactions Decrease with Increasing Looseness of the Transition Structure. J. Am. Chem. Soc. 1991, 113, 8056-8061.

41. Poirier, R. A.; Wang, Y. L.; Westaway, K. C. A Theoretical Study of the Relationship between Secondary $\alpha$-Deuterium Kinetic Isotope Effects and the Structure of $\mathrm{S}_{\mathrm{N}} 2$ Transition States. J. Am. Chem. Soc. 1994, 116, 2526-2533.

42. Glad, S. S.; Jensen, F. Transition State Looseness and $\alpha$-Secondary Kinetic Isotope Effects. J. Am. Chem. Soc. 1997, 119, 227-232.

43. Zhao, Y.; Gonzalez-Garcia, N.; Truhlar, D. G. Benchmark Database of Barrier Heights for Heavy Atom Transfer, Nucleophilic Substitution, Association, and Unimolecular Reactions and Its Use to Test Theoretical Methods. J. Phys. Chem. A 2005, 109, 2012-2018.

44. Chase, J., W. M; Davies, C. A.; Downey, J., J. R.; Frurip, D. J.; McDonald, R. A.; Syverud, A. N. JANAF Thermochemical Tables, 3rd ed. Parts I and II. J. Phys. Chem. Ref. Data 1985, Suppl. 1.

45. Linstrom, P. J., Mallard, W. G. NIST Chemistry WebBook, NIST Standard Reference Database Number 69, June 2005, National Institute of Standards and Technology, Gaithersburg MD, 20899 (http:// webbook.nist.gov).

46. Catlett, C. TeraGrid: Analysis of Organization, System Architecture, and Middleware Enabling New Types of Applications. In High Performance Computing and Grids in Action, Grandinetti, L., Ed.; IOS Press; Advances in Parallel Computing series, Amsterdam, 2007. 